\title{
EFFECT OF MAGNETIC FIELDS ON DRUG INDUCED CONTRACTILITY AND MORTALITY IN SPIROSTOMUM
}

\author{
Angela RIPAMONTI, R.B. FRANKEL \\ Francis Bitter National Magnet Laboratory ${ }^{*}$, Massachusetts Institute of Technology, Cambridge, MA 02139, USA \\ and \\ E.M. ETTIENNE ** \\ University of Massachusetts Medical School, Worcester, MA 01600, USA
}

\begin{abstract}
The influence of homogeneous magnetic fields up to $5.5 \mathrm{~T}$ on contractile frequency and mortality in the ciliate protozoan spirostomum ambiguum stimulated by 2,2' PDS is reported. Magnetic fields are observed to decrease contractile frequency and to significantly increase mortality.
\end{abstract}

Possibilities for installation of large scale magnetic levices for energy production have stimulated inquiries ato the biological effects of magnetic fields $[1,2]$. lecently magnetic fields have been reported by licking et al. [3] to influence the force developed uring contraction of isolated frog sartorius muscle. hey observed that in homogeneous magnetic fields p to $5 \mathrm{~T}$, the amplitude of isometric force developlent in isolated skeletal muscle is reduced by about 7. The authors speculate, following Dudoladov and fincher [4], that the structural state of intracellular ater adjacent to protein or membrane surfaces can altered by an external magnetic field.

We have investigated the effects of homogeneous agnetic fields on the mechanism of cellular contracon by studying the contraction frequency in cells lowing chemical stimulation with and without an plied magnetic field. In this study we used the ntractile ciliate spirostomum ambiguum (Ward's ological Supply, Rochester, NY), inducing contracons with $10 \mu \mathrm{M}$ of the thiol reagent $2,2^{\prime}$-dipyridyl-

Sponsored by the National Science Foundation Work partially sponsored by the Muscular Dystrophy Association of America. disulfide (PDS) (Sigma Chemical Co., St. Louis, MO) in a medium consisting of $2 \mu \mathrm{M} \mathrm{NaCl}, 0.5 \mu \mathrm{M} \mathrm{KCl}$; $0.05 \mu \mathrm{M} \mathrm{CaCl}_{2} ; 0.1 \mu \mathrm{M} \mathrm{KH}_{2} \mathrm{PO}_{4}$; and $0.1 \mu \mathrm{M} \mathrm{KOH}$ (pH 6.3). In all experiments, the temperature was monitored and held constant at 20 or $22^{\circ} \mathrm{C}$ during application of the field. PDS is a sulfhydryl oxidizing agent which, through action on the microsomal respiratory chain of cells [5] decreases cytoplasmic ratios of NADPH/NADP and GSH/GSSG (glutathione). These ratios have been implicated in the oscillatory regulation of ionized free calcium concentration in the cytoplasm over ranges which include threshold levels for contraction in spirostomum [6,7]. It has been demonstrated that contractility in spirostomum is fundamentally like that of striated muscle and that there is $\mathrm{Ca}^{2+}$ dependent regulation of contractile elements [8] with $\mathrm{Ca}^{2+}$ levels controlled through intracellular membranous compartments. Because its physiology has been elucidated in detail, we feel that spirostomum is an excellent organism for the study of the effects of magnetic fields on mechano-chemical activity.

Magnetic fields of 0.5 and $0.92 \mathrm{~T}$ were produced by a water-cooled electromagnet with flat, iron pole pieces and at 3.0 and $5.5 \mathrm{~T}$ by a water-cooled Bitter 


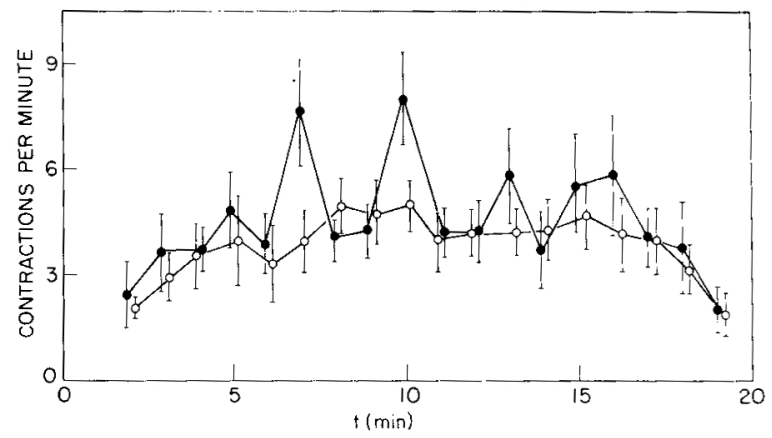

Fig. 1. Time course and magnitude of contractile response of Spirostomum to treatment with $10^{-5}$ M 2,2' PDS in zero field $(\bullet)$ and $0.92 \mathrm{~T}(0)$. Significant suppression of contractions are seen to occur at $7,10,13,15$ and $16 \mathrm{~min}$.

solenoid. PDS induced contractions per minute were monitored over an interval of $20 \mathrm{~min}$ in populations of 15 or more cells exhibiting synchronous contractions. The results per time point of 10 to 30 experiments were analyzed statistically according to the Student ' $t$ ' test [9]. The frequency of contractions as a function of time following stimulation with PDS

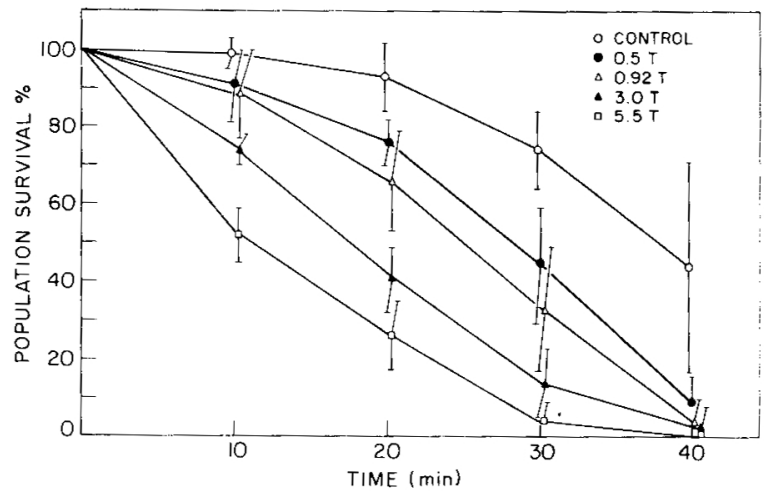

Fig. 2. Percentage survival as a function of time for cells stimulated with 2,2' PDS in homogeneous magnetic fields of $0 \mathrm{~T}$ (control), $0.5 \mathrm{~T}, 0.92 \mathrm{~T}, 3.0 \mathrm{~T}$ and $5.5 \mathrm{~T}$. The data are also tabulated in table 1 .

is shown in fig. 1 for magnetic field $H_{0}=0.92 \mathrm{~T}$ and $H_{0}=0$ controls. At 7, 10, 13 and 16 min following incubation, peaks are observed in the contraction frequency for $H_{0}=0$ (see fig. 1) [6,7]. In the external magnetic field, the values for the peak contraction frequencies are depressed by $50 \%(P<0.001), 37 \%$

Table 1

Percentage survival as a function of time following simultaneous stimulation with PDS and exposure to 0.5, 0.92, 3 and 5.5 T magnetic fields

\begin{tabular}{|c|c|c|c|c|c|}
\hline \multirow{2}{*}{$\begin{array}{l}\text { Field } \\
\text { Time } \\
(\mathrm{min})\end{array}$} & \multirow{2}{*}{$\begin{array}{l}\begin{array}{l}\text { Control }(0 \mathrm{~T}) \\
n^{*}=15\end{array} \\
\bar{x} \pm \mathrm{sd}\end{array}$} & \multicolumn{2}{|l|}{$\begin{array}{l}0.5 \mathrm{~T} \\
n^{*}=15\end{array}$} & \multicolumn{2}{|l|}{$\begin{array}{l}0.92 \mathrm{~T} \\
n^{*}=15\end{array}$} \\
\hline & & $\bar{x} \pm \mathrm{sd}$ & $\mathrm{S}^{+}$ & $\bar{x} \pm \mathrm{sd}$ & $\mathrm{S}^{+}$ \\
\hline 10 & $99 \pm 3.22$ & $91.6 \pm 9.96$ & $P<0.01$ & $89.6 \pm 12.2$ & $P<0.001$ \\
\hline 20 & $93.7 \pm 9.6$ & $76.12 \pm 5.92$ & $P<0.01$ & $66.3 \pm 13.6$ & $P<0.001$ \\
\hline 30 & $74.1 \pm 10.2$ & $44.9 \pm 15.3$ & $P<0.0005$ & $33.1 \pm 16$ & $P<0.0005$ \\
\hline 40 & $44.2 \pm 27.8$ & $7.56 \pm 8.5$ & $P<0.0005$ & $4.02 \pm 6.3$ & $P<0.0005$ \\
\hline Field & $\begin{array}{l}\text { Control }(0 \mathrm{~T}) \\
n^{*}=15\end{array}$ & $\begin{array}{l}3.0 \mathrm{~T} \\
n^{*}=10\end{array}$ & & $\begin{array}{l}5.5 \mathrm{~T} \\
n^{*}=10\end{array}$ & \\
\hline $\begin{array}{l}\text { Time } \\
(\min )\end{array}$ & $\bar{x} \pm \mathrm{sd}$ & $\bar{x} \pm \mathrm{sd}$ & $\mathrm{S}^{+}$ & $\bar{x} \pm \mathrm{sd}$ & $\mathrm{S}^{+}$ \\
\hline 10 & 99. \pm 3.22 & $74.7 \pm 4.5$ & $P<0.001$ & $52.2 \pm 7.4$ & $P<0.001$ \\
\hline 20 & $93.7 \pm 9.6$ & $41.09 \pm 8.2$ & $P<0.0005$ & $26.8 \pm 9.3$ & $P<0.0005$ \\
\hline 30 & $74.1 \pm 10.2$ & $44.3 \pm 9.5$ & $P<0.0005$ & $3.3 \pm 5.9$ & $P<0.0005$ \\
\hline 40 & $44.2 \pm 27.8$ & $2.8 \pm 5.2$ & $P<0.0005$ & $0 \pm 0$ & $P<0.0005$ \\
\hline
\end{tabular}

$n^{*}:$ Number of experiments with at least 15 cells per sample.

$\mathrm{S}^{+}$: Significance compared to control. 
$(P<0.001), 33 \%(P<0.001)$, and 33\% $(P<0.001)$, respectively. The duration of the relaxation phase in magnetic fields was qualitatively observed to be extended over controls.

In addition to the observed effects on contraction frequency, there are also very marked effects on cell mortality. In fig. 2, the percentages of survivors in 12 experiments with $>15$ cells each at $10,20,30$ and 40 min after incubation are plotted as a function of time for magnetic fields $H_{0}=0$ (control), $0.50 \mathrm{~T}$, $0.92 \mathrm{~T}, 3.0 \mathrm{~T}$ and $5.5 \mathrm{~T}$. In table 1 we present percentage survival and statistical significance compared to controls over the given time intervals for the four magnetic field values. At $30 \mathrm{~min}$, the effects of $0.50 \mathrm{~T}$, $0.92 \mathrm{~T}, 3.0 \mathrm{~T}$ and $5.5 \mathrm{~T}$ on survival were all significant to $P<0.0005$. We note that in the absence of PDS, there were no observed effects of exposure to magnetic fields up to $5.5 \mathrm{~T}$ for $30 \mathrm{~min}$ on cell viability.

Experiments were also conducted in which samples of spirostomum ( 15 cells per sample) were exposed to $5.5 \mathrm{~T}$ for $30 \mathrm{~min}$ in the absence of the drug, and then removed from the field. Immediately following field exposure, PDS was administered and the mortality in zero field was monitored as a function of time and compared with controls which had not been exposed to the external field. The results, presented in table 2 and fig. 3 , show that at $10,20,30$ and 40 min experimental values are $83 \%(P<0.001), 55 \%$ $(P<0.0005), 33 \%(P<0.0005)$ and $15 \%(P<$ $0.0005)$ of controls, respectively. These results imply that the effect of the magnetic field on mortality cannot be attributed solely to the direct effect

Table 2

Percentage survival as a function of time after PDS stimulation, following $30 \mathrm{~min}$ exposure to $5.5 \mathrm{~T}$ magnetic field

\begin{tabular}{|c|c|c|c|}
\hline & $\begin{array}{l}\text { Time } \\
(\min )\end{array}$ & $\bar{x} \pm \mathrm{sd}$ & \\
\hline $\begin{array}{l}\text { Control }(0 \mathrm{~T}) \\
n^{*}=10\end{array}$ & $\begin{array}{l}10 \\
20 \\
30 \\
40\end{array}$ & $\begin{array}{l}98.03 \pm 3.2 \\
94.1 \pm 5.9 \\
65.6 \pm 7.8 \\
46.2 \pm 22.5\end{array}$ & \\
\hline $\begin{array}{l}5.5 \mathrm{~T} \\
n^{*}=10\end{array}$ & $\begin{array}{l}10 \\
20 \\
30 \\
40\end{array}$ & $\begin{aligned} 81.4 & \pm 10.5 \\
51.8 & \pm 16.1 \\
22.2 & \pm 15.2 \\
7.1 & \pm 8.3\end{aligned}$ & $\begin{array}{l}P<0.001 \\
P<0.0005 \\
P<0.0005 \\
P<0.0005\end{array}$ \\
\hline
\end{tabular}

$n^{*}:$ number of experiments with at least 15 cells per sample. $P$ : significance compared to control.

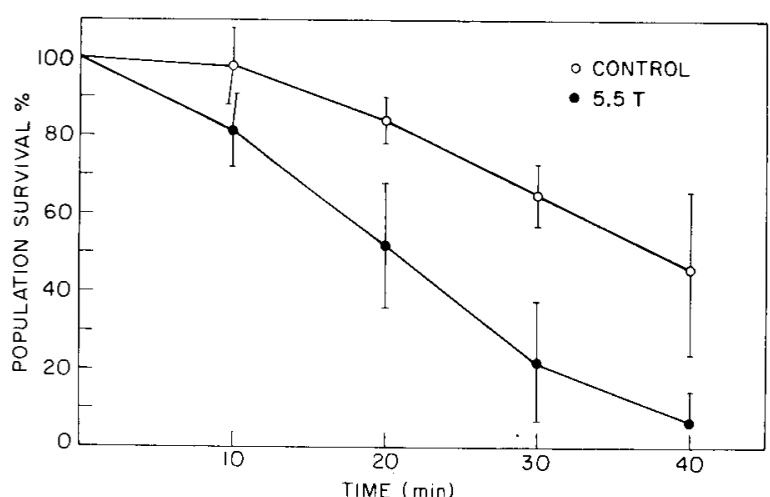

Fig. 3. Percentage survival as a function of time for cells exposed for $30 \mathrm{~min}$ to $0 \mathrm{~T}$ (controls) and $5.5 \mathrm{~T}$, followed by removal of the field and stimulation with $2,2^{\prime}$ PDS. The abscissa correspond to time following stimulation with $2,2^{\prime}$ PDS. The data are also tabulated in table 2.

of the field on PDS, and indicate significant long lasting effects of the field on the organism.

We have seen that the magnetic field acts to decrease contraction frequency and increase mortality in response to PDS. Based on the known physiology of spirostomum $[5,8]$ the observations can be interpreted as reflecting a decrease in the enzymatic transport of $\mathrm{Ca}^{2+}$ out of the cytoplasm following contraction in the magnetic field. Reduced $\mathrm{Ca}^{2+}$ transport might occur as a result of an interaction between the magnetic field and the intracellular membranous compartments. This hypothesis could be verified by observation of prolongation of $\mathrm{Ca}^{2+}$ transients in vivo. Alternatively, $\mathrm{Ca}^{2+}$ in transport vesicles isolated from cells exposed to magnetic fields could be measured in vitro with ${ }^{45} \mathrm{Ca}$. These experiments are presently being pursued. Information from these experiments will enable us to ascertain whether the locus of the magnetic field effect is associated with the $\mathrm{Ca}^{2+}$ transport membranes.

\section{Acknowledgements}

We are pleased to acknowledge the continuing interest and support of D.B. Montgomery and P. Marston, and thank Y. Shapira for a careful reading of the manuscript. 


\section{References}

[1] H. Aceto, C. Tobias and I.L. Silver, IEEE Trans. Magn. MAG-6 (1970) 368.

[2] A. Sheppard and M. Eisenbud, Biological Effects of Electric and Magnetic Fields of Extremely Low Frequency (University Press, New York, 1977).

[3] J. Bücking, M. Herbst and P. Pointer, Rad. Environ. Biophys. 11 (1974) 79.
[4] A.G. Dudoladov and K.S. Trincher, Biofiz. 16, (1971) 547.

[5] M.A. Levine and E. Ettienne, Microbios Lett. in press.

[6] E. Ettienne and S. Dikstein, Nature, 250 (1974) 782.

[7] S. Dikstein and R.B. Hawkes, Experientia 32 (1976) 1029.

[8] E.M. Ettienne, J. Gen. Physiol. 56 (1970) 168.

[9] W.C. Scheffler, Statistics for Biological Sciences (Addison Wesley, New York, 1973). 